\title{
Pulp Fiction or Hard Fact? The Development of a European Employment Policy
}

\section{Nicole Busby}

\section{Introduction}

At its meeting on 1st June 2004, the Employment, Social Policy, Health and Consumer Affairs Council reached political agreement on the latest package of employment guidelines and recommendations presented by the Commission. The guidelines for the employment policies of the member states were first presented in July 2003.' These are now accompanied by a revised set of recommendations, (European Commission 2004b) which incorporate the findings of the European Employment Taskforce chaired by Wim Kok (European Commission/European Council 2003). The recommendations provide four common goals to be taken into account by all Member States as well as individual recommendations for the pre-expansion 15. These goals are intended to strengthen the implementation of the European Employment Strategy (EES) as are the new guidelines, which have been designed to provide a 'reinforced, simplified and better-governed process'. ${ }^{2}$

The ten new guidelines, which will replace the four-pillar approach previously used, have been adopted, for the first time, as part of a package of measures that also includes proposals for the Broad Economic Policy Guidelines (BPEGs). The EES will continue to be administered and evaluated through the open method of co-ordination (OMC) which has been defined as a combination of 'broad participation in policy-making, co-ordination of multiple levels of government, use of information and benchmarking, recognition of the need for diversity, and structured but unsanctioned guidance from the Commission' (Mosher and Trubek 2003: 64). The OMC was introduced at the European level as a policy instrument designed to address employment-related problems through the application of soft law measures. This method has recently been applied to other areas of supranational policy-making requiring an alternative mode of governance (Régent 2003).

This article provides an overview of the development of the new employment package along with some observations regarding the likely effectiveness of the amendments introduced. Underpinning this analysis will be an assessment of the new emphasis given to employment policy at the European level. The formal linkage of employment with economic policy and the use of the problem-solving approach, originally designed for the employment field, as a blueprint for future policy initiatives indicate the prominence now given to this aspect of European integration. While this development is encouraging in profile-raising and agenda-setting terms, the author advises caution as the reliance on soft law mechanisms and the smoke-screen effect of such overt prominence could actually mask a retrograde step for social policy generally. Furthermore, the emphasis on job creation, if unaccompanied by hard law measures intended to provide minimum standards of employment protection, could severely compromise the quality of jobs throughout the EU. 


\section{The European Employment Strategy}

The EES is based on the Employment Title (Title VIII of Part Three) inserted into the EC Treaty by the Treaty of Amsterdam in 1997. The origins of this Title were set down in the 1993 White Paper on growth, competitiveness and employment published by the Commission under the Presidency of Jacques Delors (European Commission 1994) and seen by many as his lasting legacy. The White Paper expressly linked the three policy areas for the first time and concluded that the creation of fifteen million new jobs would be a necessary aim for the European Union in the new millennium if the key issues of growing unemployment and global competition were to be addressed. The overriding objective was to develop a joined up approach to policy-making so that employment would be integrated with other relevant areas such as fiscal policy. Structural unemployment, which was becoming a feature of many of the member states, was attributed to a combination of social and economic exclusion requiring Keynsian and supply-side measures, specifically a mix of proactive policy designed to promote a more inclusive environment and the deregulation of certain aspects of national labour markets. (European Commission 2000a).

The development of an EU-level solution was fraught with difficulty, due partly to a lack of legal competence but also because of the need to preserve the relatively generous levels of social protection found in some Member States. The 'European social model' which is based on the attainment of such protection across all member states was already under threat from the antiBrussels backlash against further expansion of the EU's competence pervasive in many countries (Mosher and Trubeck 2003: 66). Faced with this set of formidable challenges, the emergence of the EES during the late 1990s represented a series of political compromises coupled with a recognition of the need for Community-level activity.

The social policy amendments introduced by the Amsterdam Treaty in 1997 provided an opportunity to formalise the new approach. A new Title on employment was inserted into the Treaty, thus enabling an extension of EC competence in the social policy arena. The key provisions are: Article 125 which establishes the objective of a 'co-ordinated strategy'; Article 127(2) which places 'high employment' on the EC policy agenda and Article 128 which sets out the framework for developing and monitoring the 'guidelines for employment'.

The reason for the focus on employment at the Amsterdam summit has been explained as arising out of a combination of the promotion of European monetary union (EMU) and the need for a unifying project (Goetschy 1999). Despite the emphasis given to the development of an overarching employment policy at the European level, the soff law nature of the strategy has led to criticism from some quarters. Such censure certainly has currency in the present debate and will be further explored later in this paper in the context of recent developments. What is important to note at this stage is the overt movement towards the Europeanisation of national employment policies exemplified by the change of priority given to social policy issues generally. As Goetschy has observed, the policy aspects previously encompassed by the development of Social Europe 'tended to lie outside the core of national social policies, so as not to upset sensitivities concerning national sovereignty.' (Goetschy 1999: 133). The EES, perhaps because of its soft law basis rather than despite it, attempted to tackle central issues of concern to all member states regardless of the national industrial relations systems in place.

The new prominence given to employment policy, and in particular unemployment, was further developed at the Luxembourg summit in 1997 where the first employment guidelines were adopted by the Heads of State and Government following modifications to the Commission's original proposals. The approved guidelines incorporated the original four pillars of the EES: employability; entrepreneurship; adaptability and equal opportunities, which were all viewed as crucial factors in the development of sustainable job creation. At the European Council meeting in Lisbon in 2000, the member states' representatives reiterated their commitment to a new economic and social agenda by the adoption of a strategic goal for the next decade: 'to become the most competitive and dynamic knowledge-based economy in the world capable of sustainable economic growth with more and better jobs and greater social cohesion.' (European Commission 2000b).

Achievement of this goal is through co-ordination of the labour market policies of member states in an annual cycle. This process, known as the open method of co-ordination (OMC), has been defined by Frank Vandenbroucke (Belgian Minister of Pensions and Social Affairs and one of 
the main architects of the process) as 'a mutual feedback process of planning, examination, comparison and adjustment of the policies of member states, all of this on the basis of common objectives.' (cited by Zeitlin 2002).

At the start of each year, the Council approves the Commission's objectives which, until now, have been drawn up as guidelines based on the four pillars. Member states' national action plans (NAPs) are then submitted for approval. The NAPs set out how best to meet the identified objectives with the involvement of the relevant parties within the national labour market. The Commission and the Council jointly examine each action plan and report to the EU summit at the end of each year, at which time the Commission also presents a recommendation on revisions to the guidelines for the year ahead.

In 2002, the Commission issued an evaluation of the first five years of the EES, which was based on a series of independent assessments commissioned in each member state on the impact of the process on national policies (European Commission 2002a). Although this evaluation highlighted a significant improvement in labour market performance across the EU, it also acknowledged that it is difficult to determine the extent to which such improvements are attributable to the EES rather than to economic factors generally. In the five years since the introduction of the EES, 10 million new jobs have been created and 4 million less EU citizens are unemployed. As far as the member states' adherence to the guidance provided for by the EES is concerned, the indications are that there have been significant changes in national employment policies with evidence of enhanced co-ordination in the areas covered by the objectives specified in the guidelines. The areas identified by the four pillars certainly seem to have gained in prominence so that gender mainstreaming, lifelong learning and the (re)conciliation of work and family life are all issues covered, to varying degrees, by the national employment policies of member states. Furthermore, state-run employment services have developed more proactive approaches to facilitating the needs of the unemployed through the provision of training and education and tax incentives have been introduced in some member states in order to increase and maximise labour market participation.

The evaluation did, however, identify some weaknesses in the EES arising from a combination of factors such as demographic trends, regional differences, globalisation and enlargement of the Union. It has been forecast that, in order to achieve the Lisbon goal of an overall employment rate of $70 \%$ by 2010 , a further 20 million jobs need to be created. It was evident that what was required in order to pursue the ambitious Lisbon agenda within such a fast-changing economic environment was a more focused, streamlined approach with greater emphasis on a cohesive strategy.

In September 2002, the Commission adopted a Communication ${ }^{3}$ which set out the amendments to be made to the strategy in order to refocus it on its main priorities. These included, inter alia, the development of a stronger link with EU economic policy co-ordination (through the streamlining of timetables), the laying down of fewer guidelines with a broader perspective, the introduction of medium-term planning with a greater emphasis on results and outcomes and increased involvement of the social partners, local authorities and other stakeholders. In January 2003, a Communication was issued by the Commission which set out the revised EES (European Commission 2003a). This was accompanied, in 2004 , by a Communication on the streamlining of the annual economic and employment policy co-ordination cycles (European Commission 2004a). The revised EES aligns its timeframe to the medium term horizon of 2010 with a mid-term review in 2006. The strategy takes a more results-oriented approach based, where possible, on the quantitative targets agreed at Lisbon. The new employment package is aimed at achievement of these targets.

\section{The New Employment Guidelines and 2004 Recommendation}

The proposed employment guidelines focus on incorporating the key points of the Lisbon strategy into the EES, in particular through the adoption of the three main objectives of full employment; improving quality and productivity at work; and strengthening social cohesion and inclusion. In order to achieve these three objectives, the guidelines focus on 10 policy priorities: active and preventative measures for unemployed and inactive people; job creation and entrepreneurship; addressing change and promoting adaptability and mobility in the labour market; development of 
human capital and lifelong learning; labour supply and active ageing; gender equality; integrating and combating discrimination against disadvantaged people; making work pay; undeclared work; and regional employment disparities.

Under each heading, the guidelines include a range of approaches, from the setting of concrete targets for the labour market participation rates of the long-term unemployed and the educational attainment of 22-year olds, to the more abstract goals of creating more and better jobs by fostering entrepreneurship and increasing labour market participation by using the potential of all groups in the population. Attainment of the goals set out in the guidelines is further articulated in the Recommendation on the implementation of the member states' employment policies which contains common and national recommendations. The Commission's original proposals were modified following publication of the report of the European Employment Taskforce which was set up in 2003 by the Commission at the invitation of the European Council. The Taskforce's brief was to undertake 'an independent in-depth examination of key employment-related policy challenges and to identify practical reform measures that can have the most direct and immediate impact on the ability of Member States to implement the revised European Employment Strategy and to achieve its objectives and targets' (Report of the European Employment Taskforce 2003: Mandate at 7). The Taskforce, chaired by Wim Kok, presented its report to the Commission in November 2003.

In making its main recommendations, the Taskforce concentrated on the achievement of increasing employment across the Union. However, a distinction was made between the creation of new jobs in the short-term and the development of sustainable employment and productivity growth in the medium- and longer-term, with an emphasis on the latter approach. In the attainment of this goal, four key requirements were identified: to increase adaptability of workers and enterprises; to attract more people to the labour market; to invest more effectively in human capital and to ensure effective implementation of reforms through better governance. These findings have informed the Commission's redrafting of the recommendations for national employment policies.

The Recommendation consists of four common recommendations concentrated on the priorities for reform alongside individual recommendations for each member state and priorities for the acceding countries to take into account when drawing up their first NAPs. It is beyond the scope of this article to offer detailed analysis of the individual recommendations and priorities for acceding countries. The following analysis will focus on the common recommendations and their relationship to the new guidelines.

The four common recommendations are: (1) increasing adaptability of workers and enterprises; (2) attracting more people to enter and remain on the labour market; (3) investing more and more effectively in human capital and lifelong learning and; (4) ensuring effective implementation of reforms through better governance. Under the first recommendation the aim is to 'promote flexibility combined with security in the labour market by focusing on improving work organisation and the attractiveness - for employers and employees - of both standard and non-standard labour contracts to avoid the emergence of two-tier labour markets.' (European Commission 2004b: 10). Standard contracts are expressly defined as contracts of unlimited duration, whether full-time or part-time. With regard to the attraction and retention of workers, the recommendations focus on supply side mechanisms intended to adjust 'the balance between taxes and benefits.' Active ageing strategies are encouraged as are personalised services for all those seeking employment who are to be supported by 'childcare and care facilities and other measures to reconcile work and family life'. The investment in human capital is to be translated into 'ambitious policies' for raising levels of research and development intended to realise the target set by the Barcelona Council in 2002 to increase investment in R\&D to $3 \%$ of GDP. This is to be achieved through a combination of the reduction of early school leaving and the broadening of the supply of training to stimulate lifelong learning. It is envisaged that the cost of such investment should be shared between public authorities, companies and individuals. Finally, the aim of improving governance is based on the mobilisation of the support and participation of the social partners and other stakeholders in the definition of clear national policies and appropriate targets. 


\section{Self Regulation and A European Employment Policy}

The criticisms that have been levelled at the EES in the past have been centred around its soft law approach and lack of hard law sanctions which are unlikely to be able to provide the teeth to support the strategy's ambitious agenda. Whether or not such criticism is well-founded remains a matter of opinion, the undeniable improvements in European employment rates being difficult to attribute specifically to any single factor. However, if there is any substance to such allegations, the revised guidelines and recommendation do little to answer them by reiterating the overall approach previously taken. The onus on improving governance is placed firmly with the member states themselves through the identification of this aspect as one of the four key recommendations for national activity. At the European-level, the rationale for continuing on a path which incorporates a 'move away from social law and legislative initiatives, towards soft law, or rather policies aimed at employment creation which, for the most part eschew legislation' (Ashiagbor 2001: 317) appears to be the old adage 'if it ain't broke, don't fix it'. In other words, the absence of concrete proof that the EES has led to improvements in employment rates does not detract from the fact of those improvements which have taken place against a backdrop of enhanced policy co-ordination despite increasing disagreement regarding the scope of 'Social Europe' and the lack of a clear vision of its future. Rather than attempting to alter anything at grass roots level, the new employment package is aimed at entrenching the central features of the EES by firmly embedding the approach thus far developed in the EU's economic policy. Ashiagbor (2001: 317) has described the shift that has taken place at EU-level as being a move away from social law towards employment policy and the latter term certainly better describes the institutional activity that surrounds the EES. But to what extent does the EES amount to a policy at EU-level rather than a mere attempt to consolidate a wide range of diverse national labour market practices within a broad common framework?

The open method of coordination (OMC), through which the EES is enforced, has been a particular target for the criticism levelled at the strategy due to the soft law approach taken. As Ball has observed, although the member states are compelled to take the guidelines into account under the provision of Article 128(2), 'there are no formal legal sanctions for failure to do so.' (Ball 2001: 357). The Commission has described the OMC as 'an innovative method of policy delivery' with the emphasis on co-ordination amounting to a 'method improving EU governance' (European Commission 2003b: 6). As well as the obvious arguments surrounding the effectiveness of this type of governance due to its reliance on self-regulation, this approach gives rise to another questionable aspect, namely its democratic legitimacy.

The reliance on soft law measures for enforcement of the strategy means that further progress is wholly dependent on the political will of those charged with taking the process forward. This gives rise to two potential threats to the democratic process. First, a lack of political will among member states' governments could leave its progress vulnerable to the vagaries of national political systems and, second, and perhaps more importantly, decisions may be taken at the European-level without full consultation or accountability under the provisions of Title VIII. As Velluti has observed, 'The main challenge with which the European Union is confronted lies in bridging the gap between these new trans-national forms of policy making and its democratic deficit/legitimacy crisis.' (Velutti 2003: 355). It would appear that there is still some way to go in achieving this. The self-regulatory nature of OMC means that compliance with the EES rests purely on assurances made by member states to follow the guidelines set, which are admittedly subject to peer pressure. Although this process is supported by the surveillance of national activities, this is administered passively - largely by each member state self-assessing achievement of its own goals by way of the NAP process. The Commission's promotion of social dialogue as a method of regulatory development can be seen as an attempt to stem the democratic deficit but it operates, to some extent, at the expense of the European Parliament. Biagi has argued convincingly that the Commission reduced the decision-making power of the member states in the field of employment policy by introducing the process of co-ordination in place of law-making (Biagi 1998).

Perhaps the value of the OMC can best be recognised through its agenda-setting nature (Szyszczak 2000: 197) and resultant normative effect as identified, albeit cautiously, in the work of Biagi $(1998 ; 2000)$ which have contributed towards a climate of co-ordination, rather than 
'mere co-operation' (Ball 2001: 357). Its advantages are easy to see as a regulatory tool which operates in sensitive policy areas for which the top-down approach to Community law-making would never be palatable to the governments of member states. By taking a 'soffly softly' approach, this method of governance is able to link the EU agenda directly to national and local levels in areas not previously the domain of European policy-making. Mosher and Trubeck have suggested that 'the 'softness' of the mechanism make it more likely that member states will make commitments to the strategy and submit to EU level co-ordination in these sensitive policy areas.' (2003: 70). It might also be possible that soft law mechanisms could ultimately lead to legally binding decisions by smoothing the path at national-level and creating a climate of conformity to a legal norm.

Thus, the OMC can be viewed as the best way to co-ordinate diverse domestic welfare systems which cannot be compelled to adopt a particular agenda by the use of hard law. The scope for cross-national policy learning is also immense as the exchange of good practices articulated through the process of benchmarking can aid in the development of self-regulatory codes of conduct involving a diverse range of actors (Tronti 1999). Such exchange facilitates measurement and comparison of labour markets by the member states and may also 'be a means by which the worst performing countries can improve their employment performance, in part, through adopting examples of best practice' (Ashiagbor 2001: 329).

\section{Assessment of the New Employment Package}

As well as recognising the limits of the $O M C$ as a suitable form of cross-national governance operating at the European level, it is important to acknowledge the contribution made by this process in what might otherwise have been a particularly stagnant area of policy-making. The relinquishment of the legal force of regulation, which has imposed obvious limitations on the EES, was given in exchange for the opportunity to take on core areas of social policy previously the domain of national governments - but has that opportunity been fully utilised and, if so, what benefits have been forthcoming? The effectiveness of the strategy in this respect represents a useful means by which the success of the EES can be assessed. It is, therefore, worth considering the new package briefly within a framework comprising certain potential key indicators: the placement of employment policy within the economic planning process; the impact of the EES on the structure of member states' labour markets and the influence of the full employment goal on the development of national welfare systems.

The fact that certain aspects of EU policy which affect growth and job creation have remained outside of the scope of European employment policy has had a limiting effect on its progress to date. The inability of the EES to directly influence policy-making in the monetary, fiscal and wage contexts has meant that it has developed as a supply-side strategy aimed at removing structural barriers to employment, whether in the context of job creation or access to existing jobs. This reasons for this are grounded in the strategy's origin as a policy instrument designed to assist in the achievement of monetary union. The development of EMU has necessitated a withdrawal of national monetary policy coupled with limited national fiscal policy. The only remaining mechanisms for the allocation of resources at the national level are labour market and social policies, both of which must be compatible with EMU if its long-term goals are to be achieved. The EES thus emerges as an economic not a social strategy and should, therefore, stand alongside other aspects of economic policy rather than be appended to them. The streamlining of the new employment guidelines with the Broad Economic Policy Guidelines and the emphasis on medium-term orientation are certainly welcome developments which indicate a move towards a more coherent programme, but such administrative arrangements do nothing to consolidate the policy-making approach.

If employment policy has indeed been advanced at the expense of European social policy, the detrimental effects of this may become all too apparent in the trade off between economic efficiency and social justice in an agenda based on competitiveness and economic growth. The relationship between economic and employment policy is reflected in Article 128 which provides that the employment guidelines should be consistent with the BEPGs, in other words subordinated to them (de la Porte and Pochet 2004: 75). The co-ordination of the timetables for the employment and economic guidelines does not alter the hierarchical nature of the relationship between 
the two or touch the separate policy agendas (Begg 2003: 6).

Barriers to employment within the member states have presented a particular challenge to the EES which has sought to alter the structure of national labour markets through the replacement of hard law measures with soft law initiatives aimed at job creation. The recommendation that national governments should seek to increase adaptability of workers and enterprises in the formulation of national policy requires a careful balance to be struck - that of combining flexibility with security. The significant increase in employment in many member states may be partially attributable to the 'hands off' approach to regulation epitomised by the EES. However, the rise of such flexible employment has largely taken place within the low paid, part-time, temporary, and often insecure, sectors of national labour markets.

The danger of combining job creation with a shift away from social protection is that the resulting increases in employment are likely to take place at the expense of many of the policy priorities identified in the employment guidelines. For example, the lack of measures aimed at improving the quality of jobs is likely to hit those groups identified as requiring special measures, such as 'ageing workers' and other 'disadvantaged people'. Furthermore, given the high levels of occupational segregation that exist across member states, the focus on increasing productivity will do nothing to improve gender equality or overcome regional employment disparities or indeed any of the wider systemic effects of social exclusion. Surely improved security for atypical and other vulnerable workers is only possible through improved standards in employment rights necessitating hard law activity at odds with the current focus on self-regulation. Of course, the EES does not prevent national governments from developing legislative initiatives of their own and the machinery exists for the advancement of agreement at the European-level under the auspices of the social dialogue. To date, this route has amounted to three framework agreements which have culminated in directives on Parental Leave, ${ }^{4}$ Part-Time Work ${ }^{5}$ and Fixed-Term Work. ${ }^{6}$ However, the latest attempt to reach agreement on a proposal to regulate the working conditions of temporary agency workers (European Commission 2002b) failed during negotiations between ETUC and UNICE. This initiative was subsequently brought forward by the Commission as a proposed directive but was shelved due to lack of political agreement at Council-level. As this particular example demonstrates, it is unlikely that those member states with the least regulated labour markets will view the increased protection of vulnerable workers as a priority.

Under the recommendation to attract more people to enter and remain on the labour market, reference is made to adjusting the balance between taxes and benefits in order to make work 'a real option for all'. Achievement of this aim depends on the level of influence that the EES's full employment goal has in relation to the development of national welfare systems (De La Porte 2002). The EU lacks competence to introduce legislative or policy changes to national tax or benefits systems, so realisation of such adjustment rests on activity at the national level. The inclusion of such activity in the recommendations amounts to a call to member states to dismantle certain aspects of their national welfare systems coupled with the introduction of tax incentives. It is unlikely that those countries with the highest levels of social protection will acquiesce as, to do so, would strike at the heart of Social Europe and the maintenance of generous welfare states originally viewed as the goal of all member states (Mosher and Trubeck 2003: 71). Attempts to incorporate this particular recommendation into policy at the national level could be interpreted as contributing to the 'gradual erosion of social programmes and policies' feared by some (Mosher and Trubeck 2003: 64; Degryse and Pochet 2000).

\section{Conclusions}

Any assessment of whether the new employment package represents an improvement to European policy-making depends on the assessor's pre-existing opinion of the EES and its management through the OMC. The EES has been described as 'a partial strategy and a political compromise' (Mosher and Trubeck 2003: 71) and it is the original trade off between legal regulation and the opportunity to influence social policy-making in the wider context that continues to shape the agenda. The harmonisation of social standards in accordance with the model once encapsulated by 'Social Europe' has given way to policy convergence based on a common set of goals rather 
than means. This approach is further strengthened by the articulation of the subsidiarity doctrine within Protocol 7 to the Amsterdam Treaty which emerged largely as a result of the anti-Brussels backlash. The EES's role as a dynamic force in national policy-making depends on the interaction of actors at the various national levels which is subject to wide variation across member states. Its success can be measured by the extent to which it has influenced the core areas of national policy in which its engagement has been enabled by the soft law approach taken.

The Commission's engagement in core policy areas traditionally reserved by member states has come about at the expense of top down harmonisation of minimum legal standards previously undertaken through the implementation of hard law measures. Without the setting of such standards, it seems likely that the influence of European social policy on national legal systems will wither. Its replacement with policy co-ordination based on somewhat vague guidance means that the European Union's impact on social policy will become illusory rather than actual. The new emphasis on employment policy through job creation is illustrative of this trend. Such development fails to offer anything close to a 'European dimension', but rather articulates at the European level the sort of activities likely to be undertaken by member states independently. There is nothing wrong with this approach per se, and the encouragement of such activity at national level would be laudable if it were accompanied by a parallel programme of legislative action aimed at ensuring that the quality of new jobs, as well as the quantity, is to be maintained. Without such a mix, it is debatable whether the Commission's current stance amounts to a 'policy' at all either in the downsized employment sphere or the broader social context. Indeed, the focus of initiatives aimed at job creation may be ultimately responsible for a lack of progress in other areas supposedly targeted by the EES such as equal opportunities and social inclusion.

As far as improvements to the administrative management of the process are concerned, the new package certainly offers increased co-ordination with other EU policies. However, what cannot be addressed by means of the limited scope offered by the soft law approach and current concentration on the narrow field of employment is the need to develop a common level of social protection across the Union. Without such development, many of the key objectives underpinning the recommendations will remain elusive (Sciarra 2000; Scharpf 2002). The entrenchment of the EES certainly represents a move away from social law - indeed the language used throughout the strategy's documentation (and the latest package) is non-legal (Sciarra 1999: 165) making it impossible to measure success or compliance in legal terms. It is somewhat ironic that what started out as an attempt at joined up policy-making looks likely to lead to polarisation of different aspects of social policy at the European level. The Lisbon agenda, on which the EES was founded, articulated the need for 'more and better jobs' throughout Europe. While the current approach may be able to deliver the first part of that goal, without recognition of the need to maintain and improve levels of social protection, the second part may prove more difficult to achieve. 


\section{Notes}

${ }^{1}$ Decision 2003/578/EC OJ L 197/13

2 lbid, Article 4

${ }^{3} \mathrm{EU} 0210206 \mathrm{~F}$

$496 / 34 / E C$

$597 / 81 / E C$

$699 / 70 / E C$

\section{References}

Ashiagbor, D. (2001), 'EMU and the Shift in the Labour Law Agenda: from 'Social Policy' to 'Employment Policy', European Law Journal, 7 (3), 311 - 330.

Ball, S. (2001), 'The European Employment Strategy: The Will but not the Way?' Industrial Law Journal, 30 (4), 353 -374.

Biagi, M. (1998), 'The Implementation of the Amsterdam Treaty with Regard to Employment: Co-ordination or Convergence?' , International Journal of Comparative Labour Law and Industrial Relations, 14, 325 - 336.

Biagi, M. (2000), 'The Impact of European Employment Strategy on the Role of Labour Law and Industrial Relations', International Journal of Comparative Labour Law and Industrial Relations, $16,155-173$.

Begg, I. (2003), 'Hard and Soft Economic Policy Co-ordination under EMU: Problems, Paradoxes and Prospects' Working Paper Series 103, Cambridge, Center for European Studies, Harvard University.

De la Porte, C. (2002) 'Is the Open Method of Coordination Appropriate for Organising Activities at European Level in Sensitive Policy Areas?', European Law Journal, 38 -58.

De La Porte C. and Pochet, P. (2004), 'The European Employment Strategy: existing research and remaining questions', 14 (1) Journal of European Social Policy, 8 (1), 71-78.

Degryse, C. and Pochet, P. (2000), 'The Likely Impact of the IGC on European Social Policy', Newsletter on the Intergovernmental Conference, No 3, November, IGC Info., Observatoire social européen,.

European Commission (1994) Growth, Competitiveness and Employment (Delors White Paper) (COM) (93) 700 Final.

European Commission (2000a), European Employment and Social Policy: A Policy for People, D-G for Education and Culture.

European Commission (2000b) Press Release, From the Lisbon Summit to a New Social Policy Agenda, at: www.europa.eu.int/comm/employment_social/news/2000/newagenda

European Commission (2002a) Taking Stock of Five Years of the EES, COM (2002) 416 Final. European Commission (2002b) Proposal for a directive on working conditions for temporary (agency) workers, COM 2002149 Final, OJ 2002 C 203, pp. 1-5.

European Commission (2003a) The Future of the European Employment Strategy: A strategy for full employment and better jobs for all, COM (2003) 6 Final.

European Commission (2003b), Mid-term Review of the Social Policy Agenda, COM (2003) 312 Final.

European Commission (2004a), Communication on the streamlining of the annual economic and employment policy co-ordination cycles, COM (2004) 239 Final.

European Commission (2004b) Strengthening the implementation of the European Employment Strategy, COM (2004) 239 Final.

European Commission/European Council (2003) Jobs, Jobs, Jobs: Creating More Employment in Europe' Report of the European Employment Taskforce, November 2004,

https://europa.eu.int/comm/employment_social/employment_strategy/task_en.htm.

Goetschy, J. (1999) 'The European Employment Strategy: Genesis and Development', European Journal of Industrial Relations, 5 (2), 117 - 137.

Goetschy, J. (2001) 'The European Employment Strategy from Amsterdam to Stockholm: Has it Reached its Cruising Speed?', Industrial Relations Journal, 32 (5), 401 - 418

Mosher, J. and Trubek, D. (2003), 'Alternative Approaches to Governance in the EU: EU Social 
Policy and the European Employment Strategy', Journal of Common Market Studies, 41 (1), 63 - 88.

Régent, S. (2003) 'The Open Method of Co-ordination: A New Supranational Form of Governance ?', European Law Journal, 9 (2), 190 - 214.

Scharpf, F.W. (2002) 'The European Social Model: Coping with the Challenges of Diversity', Journal of Common Market Studies, 40 (4), 645 - 670.

Sciarra, S. (1999) 'The Employment Title in the Amsterdam Treaty: A Multi-Language Legal Discourse' in D. O'Keefe and P. Twomey (eds) Legal Issues of the Amsterdam Treaty, Oxford, Hart Publishing.

Sciarra, S. (2000) 'Integration through Co-ordination: The Employment Title in the Amsterdam Treaty', Columbia Journal of European Law, 6 (2), 209 - 229.

Szyszczak, E. (2000) 'The Evolving European Employment Strategy' in J. Shaw J. (ed), Social Law and Policy in an Evolving European Union, Oxford, Hart Publishing.

Tronti, L. (1999) 'Benchmarking Employment Performance and Labour Market Policies: The Results of the Research Project', Transfer: European Review of Labour and Research, 5, 542 - 562.

Velutti, S. (2003) 'Towards the Constitutionalization of New Forms of Governance: A Revised Institutional Framework for the European Employment Strategy', Yearbook of European Law, $22,353-405$.

Zeitlin, J. (2002) The Open Method of Co-ordination and the Future of the European Employment Strategy, Presentation to the Employment and Social Affairs Committee of the European Parliament on the first five year evaluation of the Employment Guidelines, 8 July 2002. 